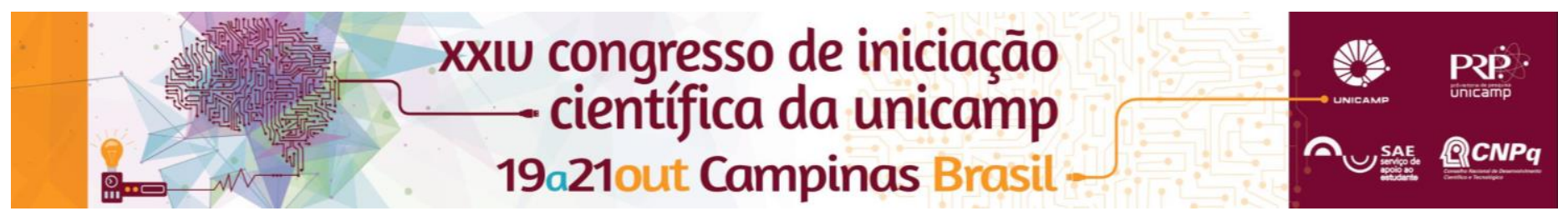

\title{
Avaliação Microestrutural de Novas Ligas de Titânio do Sistema Ti-Nb-Fe (TNF) para Aplicações Biomédicas.
}

\author{
Mariana Roveri Dal Bó*, Camilo Salvador, Rubens Caram.
}

\section{Resumo}

As ligas de titânio do tipo $\beta$ são as mais utilizadas na fabricação de dispositivos biomédicos em função de suas propriedades mecânicas e alta biocompatibilidade. Nesse estudo, $\mathrm{Nb}$ e Fe foram adicionados ao Ti visando obter a total estabilização da fase $\beta$. As ligas resultantes foram submetidas a diversas condições de processamento e caracterizadas em relação à microestrutura e ao módulo módulo de elasticidade.

\section{Palavras-chave:}

Ligas de Titânio, Transformação de Fase, Biomateriais.

\section{Introdução}

As ligas de titânio do tipo $\beta$ se destacam na fabricação de dispositivos biomédicos em função de sua boa conformabilidade a frio, elevada resistência mecânica específica e alta resistência à corrosão em meio fisiológico ${ }^{1,2}$. A estabilidade da fase $\beta$ (CCC) pode ser prevista com auxílio do mapa Bo x Md, onde Bo é a medida da força de ligação entre o titânio e outro metal e Md é o nível de energia do orbital "d" do elemento de liga $^{3}$.

Em relação $\mathrm{Ti}$, o $\mathrm{Fe}$ é classificado como um elemento $\beta$ estabilizador. A adição de $\mathrm{Fe}$ ao Ti já foi previamente investigada e foi confirmada sua eficiência na estabilização da fase $\beta^{4}$. O objetivo deste trabalho é investigar novas composições no sistema Ti-Nb-Fe.

\section{Resultados e Discussão}

As amostras apresentadas na tabela 1 foram inicialmente submetidas à solubilização a $800^{\circ} \mathrm{C}$ por 30 min e em seguida, resfriadas em água ou em forno. $O$ segundo tratamento térmico aplicado às amostras é conhecido como "step-quenching" e envolve a solubilização $\left(900^{\circ} \mathrm{C}\right)$ seguida pelo envelhecimento isotérmico executado diretamente após a solubilização, $\mathrm{O}$ tempo de isoterma direta foi de $30 \mathrm{~min}$ e realizados às temperaturas de $350^{\circ} \mathrm{C}, 450^{\circ} \mathrm{C}$ e $550^{\circ} \mathrm{C}$.

Tabela 1. Análise de Fluorescência das ligas trabalhadas.

\begin{tabular}{c|c|ccc}
\hline Liga & Nb/Fe at. & $\mathbf{T i}$ & $\mathbf{N b}$ & $\mathbf{F e}$ \\
\hline Ti-31Nb-1,0Fe & 18,64 & Bal. & $29,9 \pm 0,2$ & $1,10 \pm 0,04$ \\
Ti-27Nb-1,5Fe & 10,82 & Bal. & $26,7 \pm 0,5$ & $1,4 \pm 0,03$ \\
Ti-23Nb-2,0Fe & 6,91 & Bal. & $22,8 \pm 0,4$ & $2,24 \pm 0,09$ \\
Ti-19Nb-2,5Fe & 4,57 & Bal. & $18,3 \pm 0,2$ & $2,69 \pm 0,04$ \\
Ti-15Nb-3,0Fe & 3,00 & Bal. & $14,8 \pm 0,2$ & $3,02 \pm 0,04$ \\
Ti-11Nb-3,5Fe & 1,89 & Bal. & $11,0 \pm 0,1$ & $3,68 \pm 0,05$ \\
\hline
\end{tabular}

Analisando as figuras 1 e 2, percebe-se que o crescimento mais fino e menos intenso das agulhas da fase $\alpha$ resulta em redução do módulo de elasticidade, sem alterar a dureza da liga Ti-19Nb-2,5Fe.

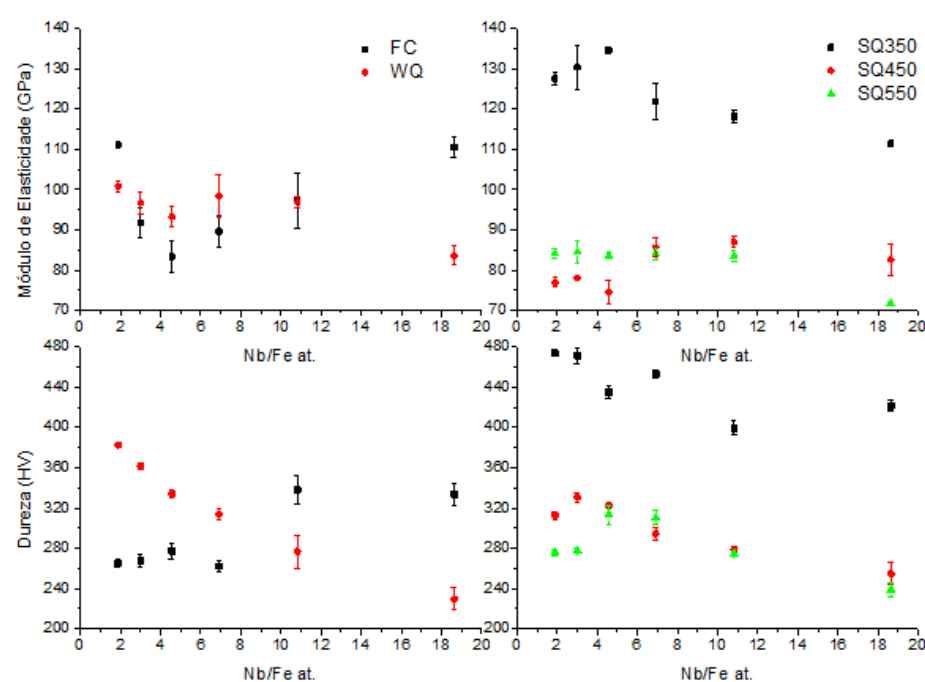

Figura 1. Dureza Vickers e módulo de elasticidade das ligas estudadas sob diversas condições.
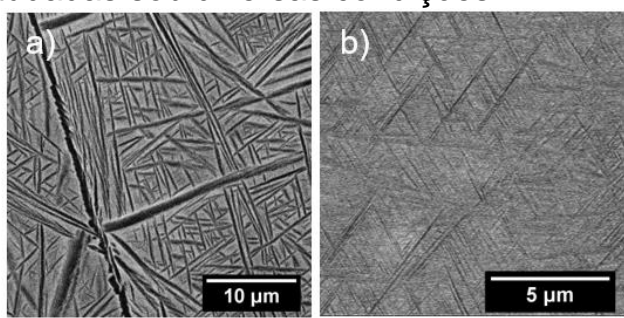

Figura 2. Efeitos da solubilização a $900^{\circ} \mathrm{C}$ na microestrutura da Ti-19Nb-2,5Fe: (a) resfriamento em forno e (b) envelhecimento a $450^{\circ} \mathrm{C}$.

\section{Conclusões}

As condições de tratamento térmico influenciam a formação e o crescimento das fases na microestrutura da liga Ti-19Nb-2,5Fe. Ao observar a variação das microestruturas, nota-se a alteração de dureza e módulo, que exibem tendências semelhantes.

\section{Agradecimentos}

A realização deste trabalho foi possível graças ao PibicCnpq, à Unicamp, à Faculdade de Engenharia Mecânica e à equipe do Laboratório de Metalurgia Física da Unicamp.

\footnotetext{
${ }^{1}$ Lopes, E. S. N. Unicamp, 2013.

2 . Niinomi, M.; Nakai , M.; Hieda, J. Acta Biomater, 2012, v. 8, 3888 -3903.

${ }^{3}$ Moffat, D. L.; Kattner, U. R., Metall. Transacitions A, 1988, v. 19A, 1988 2389.

${ }^{4}$ Lee, C. M.; Ho, W. F.; Ju, C. P.; Chern Lin, J. H. J. Mater. Sci. Mater. Med. 2002, v. 13, 695-700.
} 